\title{
Transitions in higher education with technology and learning: methods for elicitation
}

Gemma Towle and Rob Howe, University of Northampton

\begin{abstract}
The e-Learning for Learners $(E 4 L)$ project, funded by the Joint Information Systems Committee (JISC) which ran from 2007-2009, investigated learners' perspectives and experiences of elearning. The learners who participated in the project were sampled as to their proficiency as ecommunicators and assessed through their completion of specific tasks in a virtual learning environment. This article discusses the methodology from this project relating to transitions and technology regarding participants from higher education. The interview plus method using personal education flowcharts (PEFs) is discussed as well as the use of product cards which were successful in eliciting data. Identification of different skill and confidence levels of learners using technology for learning through the aid of PEFs helps to recognise challenges and issues in transitions and would allow institutions and educators to tailor skills training.
\end{abstract}

Keywords: e-learning; learners' experiences of technology; transitions; personal education flowchart.

\section{Introduction}

This article explores the idea of HE transitions in relation to technology and learning. The eLearning for Learners (E4L) project established that there are many different types of transitions within an educational journey. Of these, three of the most common are: from course to course, institution to institution and year to year within a course. Of course, these can become more complex and include learners who may change institutions within a course but these are less common. The literature focuses primarily on the learner's transition to university (Laing et al, 2005, Abramson \& Jones 2001, Hoyles 2001) and from university (Jindal-Snape \& Holmes 2009, Holden and Hamblett 2007, Tinto 1993). Less investigation has been undertaken regarding the other transitions which were identified by the project. The significance and focus of the transitions discussed in the literature varies from social interaction (Horsmanshof, 2004; Robinson et al 2009; Smailes et al. 2009) to skills development (Burgess 2009; Cohen and Bobrowicz, 2009; Whitton 2009). In contrast, the research perspective of the E4L project focussed on transitions in relation to technology.

\section{Project background}

The E4L project was a two year Joint Information Systems Committee (JISC) funded project which completed at the end of February 2009. It was one of seven under the JISC learner experiences of e-learning programme, phase 2. Phase 1 consisted of: a research project regarding the learners' experiences of e-learning (LEX); a study into the learners' experiences in subject 
specific areas (LearnerXP); a scoping study to provide background and methodology for further study on learners' experiences of e-learning: and the Learners' Voices video clips. The results from phase 1 identified areas that were worthy of further exploration and that could not have been carried out by the phase 1 projects alone. As such phase 2 was created and consisted of seven funded projects across the UK collecting data from learners and further exploring the gaps found from the phase 1 projects, $E 4 L$ being one of them.

The project's aim was to investigate learners' opinions and experiences about e-learning particularly relating to three core themes of their transitional periods; use of shadow technologies (technologies which students use alongside those recommended or provided by their institutions); and light bulb moments (moments of inspiration which highlight to learners the benefits of using technology to aid learning). As the E4L project progressed the opposite of the lightbulb moments were also explored - darklight moments. These were moments that learners found the technology to be so de-motivational that they were discouraged from using the technology again. The project gathered data from three educational levels of learners: those in Further Education (FE), Higher Education (HE) and those undertaking adult and community learning (ACL) in order to obtain a broad view of learners across levels and within the county of Northamptonshire. In order to attain a representative section of these learners a sampling method was used.

\section{Sampling}

In order to provide cohesion with the other projects and due to project limitations, a specific type of learner was required for participation. Originally the project was going to focus on those deemed to be 'effective e-learners'. However ascertaining what constitutes an e-learner was problematic as the literature lacked clarity on this issue. Of the literature at the time, the Learner Experiences of e-learning (LEX) project had made an attempt at defining these learners. LEX was part of the JISC funded learner experience phase one projects and they explored learner perspectives and experiences on e-learning. Part of their findings included some characteristics of effective e-learners (Creanor et al, 2006). Although the LEX project had provided some characteristics it was decided that there was not enough clear definition to use as a valid way of assessing effective e-learners. What the project did provide was a starting point and it was noted that communication played an important role in the learner's experiences. This emphasis on the importance of communication was further echoed in literature for learning both with and without technology (Greener, 2009; Laurillard, 1993; Mason, 2004; Oblinger and Oblinger, 2005). The project team therefore decided to focus on learners who could be defined as 'proficient ecommunicators'. Those would be learners who could demonstrate to a measurable level their competence and skills in communicating in an electronic environment.

As the concept of proficient e-communicators needed to be measurable for sampling and project participation a number of different models related to communication and learning were examined for suitability. These included Mayes Conceptualisation Cycle (Mayes and Fowler, 1999) which was disregarded primarily because communication was only a single element of the cycle; Laurillard's Conversational Framework (2002) required multiple interactions from potential participants and was found to be not feasible for sampling in the short time available; and Salmon's Five Step Model (2002) which best fitted the research question and was the one selected. 
Salmon's model enabled the project team to assess possible participants based on their capability and motivation to complete some basic online tasks. Utilising the University of Northampton's Blackboard based virtual learning environment (VLE) entitled NILE (Northampton Integrated Learning Environment) a number of tasks corresponding to each of Salmon's steps were created and completed by potential participants. These tasks included accessing the site, filling in a questionnaire, posting in a discussion area and adding an entry to a wiki (Towle \& Howe 2008). Access and motivation was the first step and demonstrated by those who were motivated and technology-literate enough to log on to the site within the VLE. The second step involved online socialisation through discussion board posts and the third assessed through posting information to a wiki and emailing answers to the researcher. The questionnaire allowed the project team to also sample the potential participants for other aspects including demographics. Those participants who successfully completed the tasks within the first three steps were deemed to be at an acceptable proficiency level which is consistent with the findings of previous research (Creanor et al, 2006) Sampling of the potential participants was step 1 of a variety of methods utilised by the project.

\section{Methodology}

The E4L project considered a number of different methods to elicit the learners' voice. We were conscious HE students are inundated with requests to take part in surveys, questionnaires and research. As institutions endeavour to improve the learning experience and gain feedback on their services, this can lead to an overload of request for data. Due to this, obtaining participation in research can be problematic (MacDougall \& Fudge 2001). The project wanted to obtain data from the learners in a way that would engage them and which they would find interesting whilst providing the most useful and accurate data for analysis. As the learner's voice was the focus of the research, data in qualitative format was central. Methods associated with the collection of qualitative data were considered and the project team decided that one of the primary methods would be semi-structured individual interviews. Reasons for this decision included the fact that a wide variety of learners were required and their educational status ranged from full-time education to one two hour teaching session a week. This also meant that the availability for them to participate in the project varied. Other constraints that dictated the methodology included the life-span of the project, what incentives could be offered and the main themes that the project was trying to investigate.

Post-sampling, learners were asked to participate in focus groups which were attended on average by six to eight learners. In all, we engaged with 26 students. The focus groups were semi-structured and recorded using audio and video according to participants' consent. The focus groups helped to provide background to the learners' experiences and allowed for the creation of the product cards which are discussed later. The primary method utilised was recorded semistructured individual interviews. This article focuses primarily on PEFs and product cards as this was the methods chosen for use within the interviews.

Personal Education Flowcharts (PEFs) 
Before their interviews, the participants in the project were asked to complete an interview plus artefact. The LEX project had used a variation of this in phase 1 and described the approach as "where the "plus" represents some artefact or activity chosen to guide recall or aid thinking aloud' (Creanor et al, 2006). Example methods include audio-logs, blogs or a learner's work. For E4L the participants were asked to complete a Personal Education Flowchart (PEF). This consisted of a flowchart of the individual's educational journey as well as information about the hardware and software they had used at each stage. Examples of these are explained later. The use of the PEF as an interview plus artefact had a number of advantages: if the learner created the PEF immediately before the interview they focused on and begin to think about their technology use before the interview formally started; it provided information about the learner's educational journey, transitions and background that might not have been recorded through questioning alone; and the interviewer could easily see any changes in the use of technology and question the learner accordingly. However, the interview plus method can also come with challenges; the interviewer needs to appreciate and understand the context that the artefact was provided in and its implications (for example, the changes in qualifications in the UK), the interviewer needs time to study the artefact produced by the learner and consider appropriate questions, if the artefact is handwritten then there can be difficulties in coherence - not everyone has decipherable handwriting. Despite the challenges that can be found by using an interview plus approach, the $E 4 L$ project found it to be an invaluable method with which to elicit data and one that can be used as a foundation for use with other methods, including product cards.

\section{Product cards}

The E4L project used product cards during the interview. These were cards that contained the names of different hardware and software that learners had stated in the focus groups that they had used. The cards were used at the beginning of their individual interviews. The learners were asked to firstly sort through the cards relating to hardware, selecting those they used or had previously used and then those related to software. If there was any technology that they used that was not written on any of the cards they wrote them on blank ones and added them to the collection. However, this only occurred twice and related to specialist software associated with computer programming that other learners who had used the cards previously were unlikely to have used. What resulted from the selection of the cards was an increase in the number of software and hardware listed by the learner from the card sort compared to their PEF.

The information the learner remembered and included in the PEF was limited to what they remembered they used when they sorted the product cards. What also became evident was that learners did not necessarily initially consider some types of technologies they used when they learnt, for example, using a television to watch a programme related to their field of study. As many of the participants commented, they did not realise that they used these technologies to aid learning as they were ubiquitous to their lives. When considering technologies for learning they primarily thought of computers. In order to identify technologies used or no longer used after a transition, a broader view should be taken and product cards can aid this.

Terminology is also part of this, when learners were interviewed they were asked 'what technology do you use when you learn' instead of 'what e-learning tools do you use'. This then broadens the concept beyond the traditional concept of e-learning as merely computers and online activities. The product cards were used more as a memory aid for the learners and 
provided information that could only have been gained through other more time intensive methods such as observation. But, in conjunction with the PEFs, they helped to provide a greater holistic view of the learners' individual journeys and transitions.

\section{Understanding individual transitions: Sophie's journey}

Every learner is an individual with different experiences, skills and backgrounds. In order to help learners on their educational journeys it is beneficial to understand their histories. PEFs from participants of the E4L project and data taken during interviews will now be used to illustrate the methods and highlight some of the issues with transitions.

Sophie is about to start the second year of her degree in English. She completed her GCSEs and then A levels at her local sixth form college before moving straight on to her degree. But how do we find out in greater depth about her transitions, particularly when it comes to her use of technology?

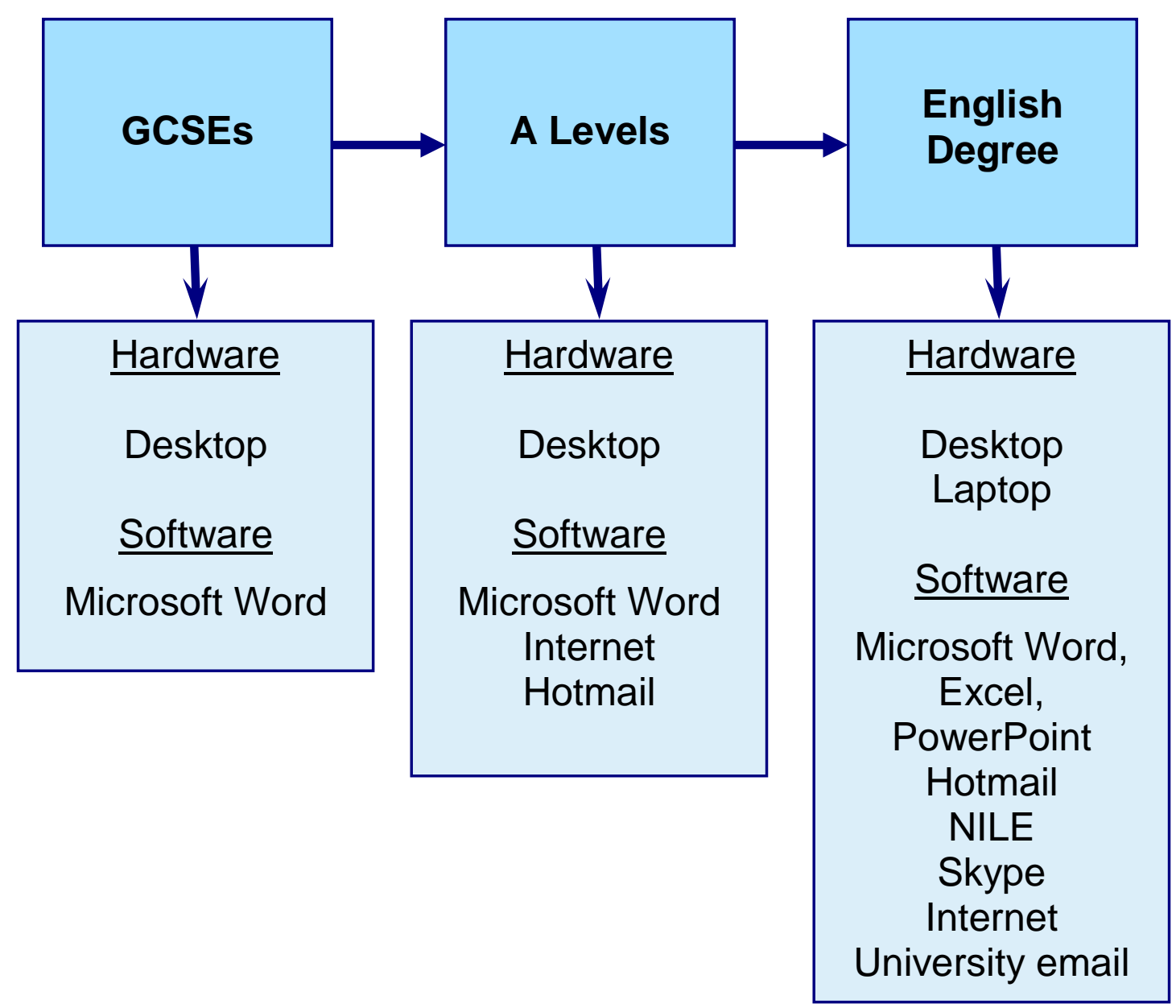

\section{Figure 1: Sophie's PEF}

In examining Figure 1, the basic flowchart of Sophie's educational journey is evident from her GCSEs to degree. The inclusion of the hardware and software on the PEF that she used at each 
educational stage helps to illustrate the change in the technology she used. For example, it is not until she reaches university that she begins to use a laptop and Skype. This increase of technology use as learners went through the transition of phase to phase and institution to institution, was evident from data received from all learners on the E4L project. When questioned during their interviews, learners were more explicit and detailed as to the reasons for those changes:

For GCSEs I didn't really use the Internet because we didn't have to really research anything and we didn't have to e-mail people because in a school you just have to go to the lessons, you don't have to do anything outside of school really. (Ben, at university)

I think that with GCSEs it's not as intense. Most of your work is just typing up a quick essay, you don't have to do much research. Whereas when I did A-Levels, especially Psychology, I had to research a lot of background case studies so I needed the Internet and laptop to take with me. Especially with A-Levels computers were very limited so if you needed a computer it was best to have a laptop.... I use more things now. (Nikki at university)

As apparent from both Ben and Nikki's comments, as they changed institutions and also progressed to higher educational levels, their technology use changed because of the associated needs. These needs included not only having a growing social network and need to keep in contact with colleagues as mentioned by Ben. But also the changing nature of the studying they undertake, as evident with Nikki's comment. She talks about how as she has developed on her education journey and compares the different levels of technology she needs to use, not only because of the demands of the courses she took, but her need for access to technology. One aspect that would have made her transition easier here from GCSEs to A levels would have been greater access to technical facilities. The requirements of both the institution and the course play a key part in the change in technology use by learners:

Yes, I use the discussion boards for one of the English modules because that's where we have to post assignments, on the discussion board. You have to talk about these pictures, about how they relate to a poem and then post your response on the discussion board. (Bobby at university)

Bobby's comment illustrates how she has to use certain technology in order to complete assignments, a requirement of her course. Sophie also undertakes an English course and identified that her use of technology such as NILE (the institution's VLE) was determined by her course and institution.

These requirements of learners can range from the need for work to be word processed to using specialised software required by their course. Identifying whether students have experience of technologies would also help to highlight where they require training. A more detailed PEF which included rating on skills level would further develop this. A key conclusion is, we cannot assume that learners have necessarily used either the hardware or software before. Aspects including word processing skills which may be ubiquitous to some can be alien to others. Not everyone has the same educational journey as evident in the next section which discusses the PEF of Amadeus. 


\section{Understanding individual transitions: Amadeus' journey}

Amadeus completed his GCSEs, after which he took an eight year break from education and worked as a care assistant before spending the last three years working on his A levels at evening classes. He has just started his first year in a degree in adult nursing. His PEF can be seen in Figure 2 below.

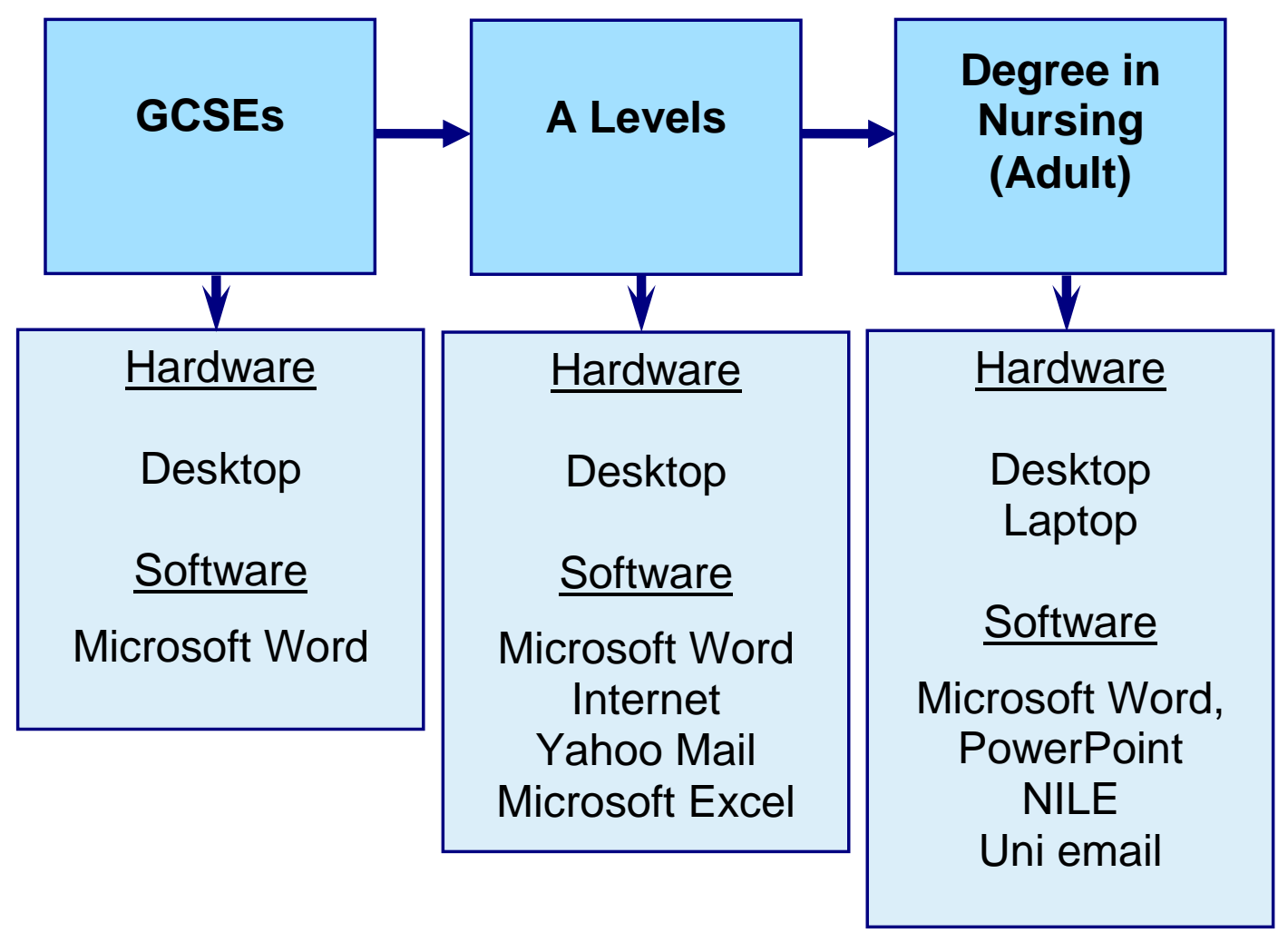

\section{Figure 2: Amadeus' PEF}

As apparent from Amadeus's PEF, his technology use has increased with his education journey and when questioned further, aspects such as technical confidence and competence can be explored. Amadeus elaborated during his interview he did not feel confident around technology and that the move into a higher education environment caused anxiety. It would have been beneficial for Amadeus if this anxiety and skill level was assessed earlier to ease his transition. This is not true of all learners:

I pretty much got a lot of it at home because I'm into my computers and cars and stuff so a lot of the technology I've pretty much had for a little while... I use them pretty much every day of my 
life to be honest. If I don't use it at university, I'm using it at work; computers, tills, stuff like that. Even stuff like televisions, I just use them all the time. (Tim at university)

Tim comments on his familiarity with technology and the fact that technology plays an integral part in his everyday life. However this is not true of all learners. Equally, knowing the proficiency and confidence of Tim helps us to understand and appreciate that not everyone needs the same technology training to make transitions easier.

\section{Conclusion}

Technology today plays an integral part of learning and is more prevalent in everyday life. Equally, learning is now life-long and people have individual and often unique educational journeys with different types of transitions. Sophie and Amadeus's PEFs illustrate a sample of basic journeys. What the PEFs can also be adapted for are transitions between year to year on a course or even module to module. These can not only be beneficial for educators and institutions but also for students to keep a track of what technology they've used and how their needs have changed. So they themselves can identify issues and challenges that might make transitions or have made transitions difficult. PEFs may be modified to identify aspects including skills training requirements and expanded to identify technology use in a work-based context. Examples of PEFs from learners could also be used in course and module design to help educators and institution appreciate the needs of their learners. When used with other methods such as product cards and individual interviews, areas related to technology and transitions can be explored in greater detail.

Video bytes of the learners themselves talking about their transitions, as well as other areas including 'light bulb moments,' is an E4L project output that is freely available. Interactive case studies are themed, and categorised video and audio clips of learners talking about their experiences with technology and learning complete with transcripts and the ability to leave comments are available at: www.northampton.ac.uk/e4l/ics

\section{References}

Abramson, M. and Jones, P. (2001) 'Getting students off to a flying start: improving the retention of advanced GNVQ students entering higher education', Widening Participation and Lifelong Learning. 3 (2): 34-37.

Burgess, M. (2009). 'Using WebCT as a Supplemental Tool to Enhance Critical Thinking and Engagement among Developmental Reading Students', Journal of College Reading and Learning. 39 (2): 9-33. Texas State University: San Marcos.

Cohen, J. and Bobrowicz, A. (2009). Enhancing student engagement with online resources: case study of using the Assignment Survival Kit (ASK) essay writing tool with first year undergraduate Multimedia Technology and Design Students, Proceedings from 6th LDHEN Symposium: Bournemouth University "The Challenge of Learning Development", 6th and 7th April 2009. [Retrieved 01 February 2010 from: http://www.aldinhe.ac.uk/bmth09/papers/cohen_bobrowicz_paper.pdf] 
Creanor, L., et al. (2006). 'LEX. The learner experience of e-learning. Final Project Report,' JISC. [Retrieved 01 February 2010 from:

http://www.jisc.ac.uk/whatwedo/programmes/elearning_pedagogy/elp_les.aspx]

Currant, B. And Kennan, C. (2009). 'Evaluating systematic transition to higher education'. Brookes eJournal of learning and teaching. 2 (4). [Retrieved 1 February 2010, http://bejlt.brookes.ac.uk/article/evaluating_systematic_transition_to_higher_education/]

Greener, S., (2009). 'Talking online: reflecting on online communication tools'. Campus-Wide Information Systems. 26, (3): 178-190.

Holden, R. and Hamblett, J. (2007). 'The transitions from higher education into work: tales of cohesion and fragmentation'. Education and Training. 49 (7): 516-585.

Horstmanshof, L., (2004). Using SMS as a way of providing connection and community for first year students, Proceedings of the 21st ASCILITE Conference. Perth, Western Australia, 5-8 December: ASCILITE. Retrieved 01 February 2010 from: http://www.ascilite.org.au/conferences/perth04/procs/contents.html].

Hoyles, C. Newman, K. and Noss, R. (2001) 'Changing patterns of transition from school to university mathematics'. International Journal of Mathematical Education in Science and Technology. 32 (6): 829-845.

Jindal-Snape, D. \& Holmes, E. (2009) 'Experience of reflection during transition from higher education to professional practice’. Reflective Practice. 10, (2): 219-232.

Laing, C. Robinson, A. and Johnston, V. (2005), 'Managing the transition into higher education: An online Spiral Induction Programme'. Active Learning in Higher Education. 6, (3): 243-255.

Laurillard, D., (1993). Rethinking university teaching: a framework for the effective use of information technology. London, UK: Routledge.

MacDougall, C., and Fudge, E., (2001) 'Planning and recruiting the sample for focus groups and in-depth interviews'. Qualitative Health Research. 11, (1): 117-126.

Mason, R., (1994). Using Communications Media in Open and Flexible Learning. London, UK: Kogan Page.

Mayes, T., and Fowler., (1999). 'Learning technology and usability: a framework for understanding courseware'. Interacting with computer. 11, (5): 485-497.

Oblinger, D. and Oblinger, J (eds.) (2005). 'Educating the net generation'. Educause. [Retrieved 01 February 2010 from: http://www.educause.edu/educatingthenetgen]

Robinson, L. et al., (2009). Supporting socialisation in the transition to university: A potential use for on-line discussion boards, Radiography. 16, (1): 48-55. 
Salmon, G., (2002). E-tivities: The key to active online learning. London: Kogan Page.

Smailes, J. et al., (2008). Virtual Mentor: an innovation in student support?, Proceedings of the Making Connections Conference 6 November 2008.

Tinto, V., (1999). Leaving College: Rethinking the Causes and Cures of Student Attrition. $2^{\text {nd }}$ edition, Chicago: University of Chicago Press.

Towle, G. \& Howe, R. (2008). E-communicators in an e-learning environment. Paper presented to: International Association for Development of the Information Society (IADIS) International Conference e-Society 2008, Algarve, Portugal, 9-12 April 2008.

Whitton, N., (2009). Alternate Reality Games for Orientation, Socialisation and Induction (ARGOSI), JISC. [Retrieved 01 February 2010 from:

http://www.jisc.ac.uk/media/documents/programmes/usersandinnovation/argosifinalreport.pdf]

\section{About the authors}

Dr Gemma Towle is Senior Research Associate in the Department of Information Services at the University of Northampton.

Email: gemma.towle@northampton.ac.uk

Rob Howe is Head of Learning Technology and Media Support in the Department of Information Services at the University of Northampton, and a University Teaching Fellow. 